\title{
Open surgical repair of multiple tuberculous mycotic aneurysms of the thoracoabdominal aorta
}

\author{
Bashi V. Velayudhan, MBBS, MS, MCh, A. Mohammed Idhrees, MBBS, MS, MCh, \\ Debasish Sahu, MBBS, MS, MCh, and Aju Jacob, MBBS, MD, Chennai, India
}

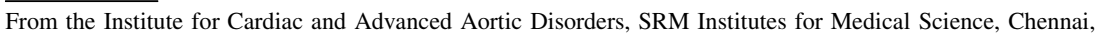
India.

Disclosures: Authors have nothing to disclose with regard to commercial support.

Received for publication April 19, 2016; revisions received May 20, 2016; accepted for publication June 5, 2016; available ahead of print July 12, 2016.

Address for reprints: A. Mohammed Idhrees, MBBS, MS, MCh, Institute for Cardiac and Advanced Aortic Disorders, SRM Institute of Medical Sciences, Chennai, India (E-mail: a.m.idhrees@gmail.com).

J Thorac Cardiovasc Surg 2016;152:e95-8

$0022-5223 / \$ 36.00$

Copyright (C) 2016 by The American Association for Thoracic Surgery

http://dx.doi.org/10.1016/j.jtcvs.2016.06.013

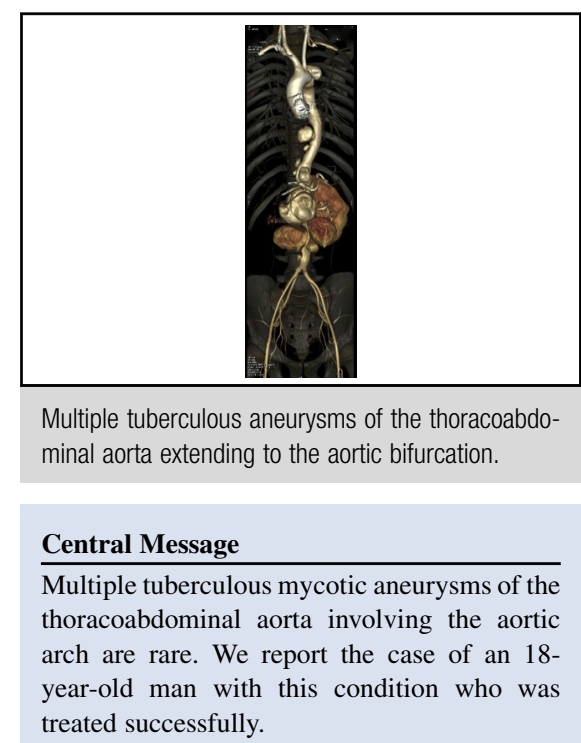

See Editorial Commentary page e98.
India is the country with the highest burden of tuberculosis (TB). The World Health Organization, in 2014, reported an estimated incidence of 2.2 million cases of TB in India out of a global incidence of 9 million. About $40 \%$ of the Indian population is infected with TB bacteria, the vast majority of whom have latent rather than active TB. The first case of TB was reported in 1819 by Laennec, and in 1882, the first case of tuberculous mycotic aneurysm of the aorta was reported. Symptomatic tuberculous aneurysms are rare, but can be fatal if not diagnosed and treated. We report the case of a patient with multiple tuberculous mycotic aneurysms of the aorta extending from the distal aortic arch to the aortic bifurcation that were treated successfully by open surgery.

\section{CLINICAL SUMMARY}

An 18-year-old man who was receiving treatment for pulmonary TB presented to us with abdominal pain. Evaluation showed multiple tuberculous aneurysms of the aorta from the distal aortic arch up to the level of the aortic bificuration. Also present were occlusion of the left subclavian artery, inferior mesenteric artery, and the right renal artery. This could have been due to thrombotic occlusion secondary to inflammation of the arteries and per-arterial tissues. There was also ostial stenosis of the left renal artery (Figure 1). Open surgical repair was performed. The aneurysms were exposed extraperitoneally by a classic thoracoabdominal incision through the left sixth intercostal space. Additionally, exposure of the aortic arch was done through the left third intercostal space. Using the left common iliac artery and the left femoral vein, cardiopulmonary bypass was instituted. The patient was cooled to $15^{\circ} \mathrm{C}$. The pericardium was opened anterior to the left phrenic nerve. A cardiac vent was placed through the left pulmonary vein and myocardial protection was done by custodial cardioplegia through the aortic root after crossclamping the same. Under deep hypothermic circulatory arrest lasting 17 minutes, the distal arch was reconstructed and upper body perfusion was restarted. The left renal artery was anastomosed beyond the stenotic segment using an interposition polyethylene terephthalate graft. While the patient was being rewarmed, reimplantation of 2 sets of intercostal arteries and visceral vessels was performed (Figure 2). The left subclavian artery was not anastmosed for 2 reasons: the intrathoraic part was diffusely diseased and thrombosed, and the right vertebral artery was dominant (Video 1).

The patient's postoperative recovery was uneventful and he was discharged from the hospital on the 12th postoperative day. The histopathology analysis of a sample from the wall of the aneurysm revealed evidence of granulomatous inflammatory reaction with no Langhans giant cells. However, culture of the aortic tissue was positive for mycobacterium. The patient received antitubercular therapy for 6 months postoperatively, is symptom-free, and doing well. 

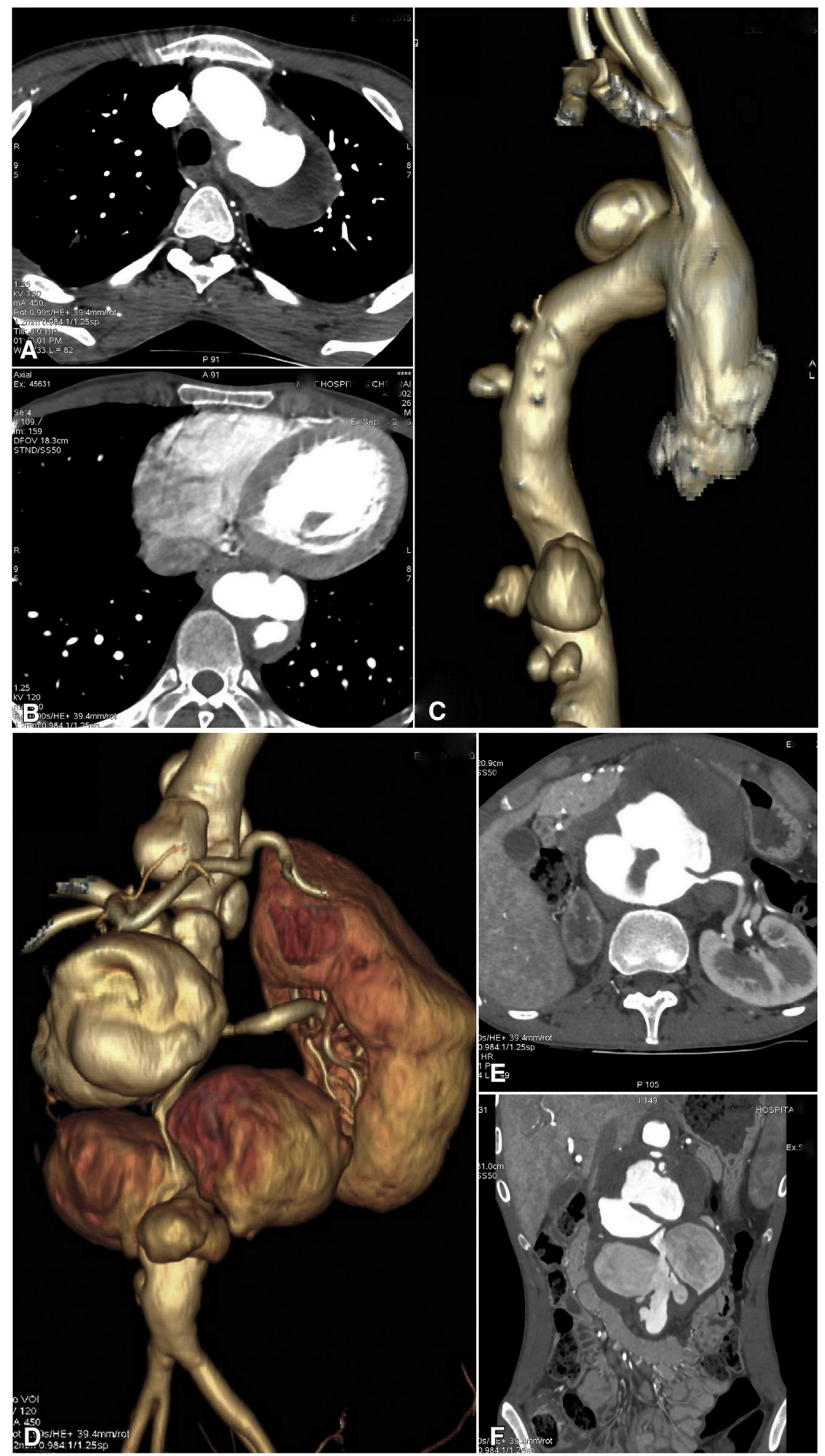

FIGURE 1. A, Axial section showing the arch aneurysm. B, Axial section showing the aneurysmal intercostal artery. C, Three-dimensional reconstruction of the thoracic aorta showing multiple aneurysms extending from the distal arch. D, Three-dimensional reconstruction of the abdominal aorta showing multiple large saccular aneurysms. E, Axial section showing the origin of the left renal artery from an aneurysm with ostial stenois. F, Coronal section showing multiple large saccular aneurysms of the abdominal aorta. 

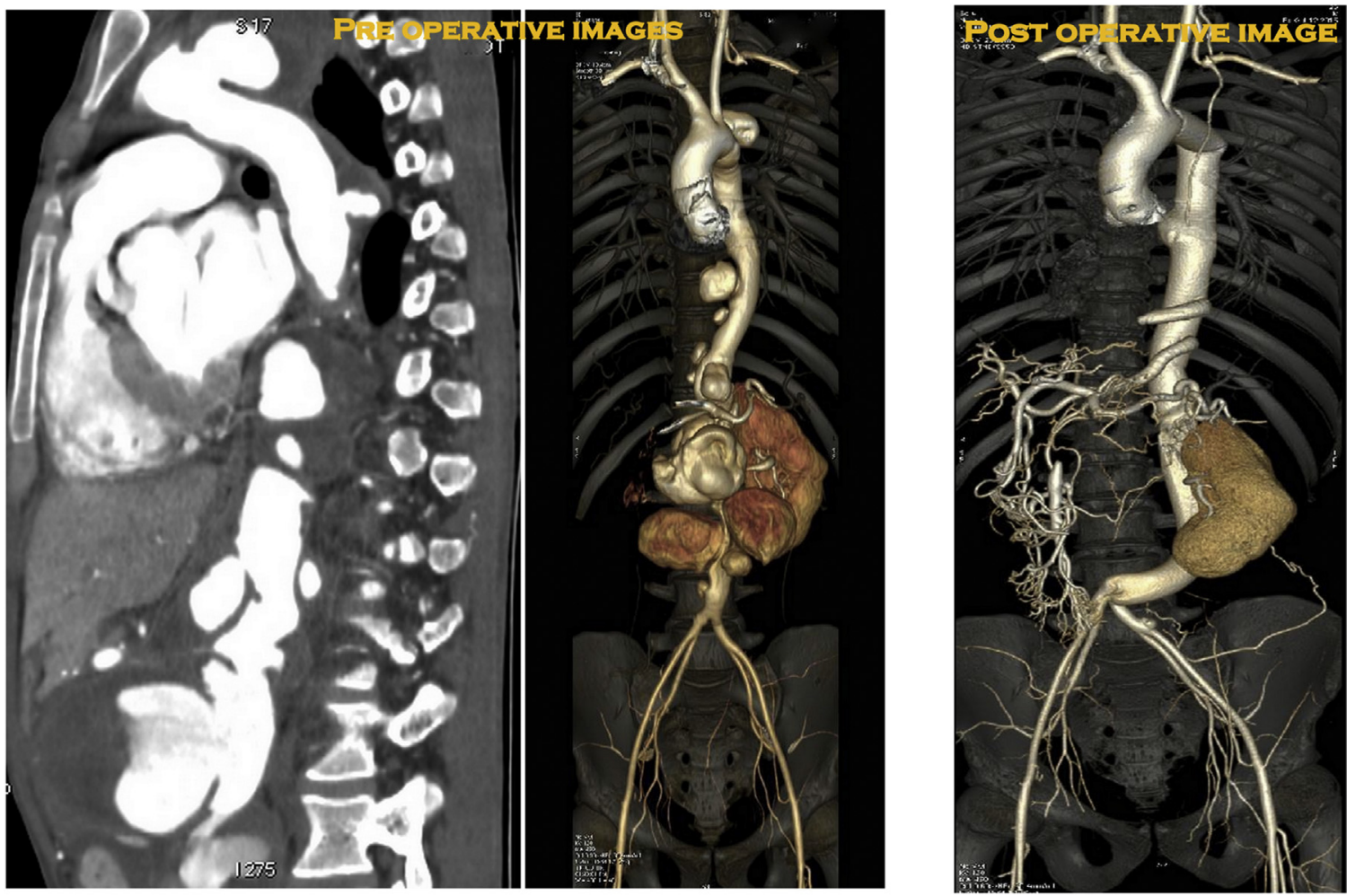

FIGURE 2. Left, Sagittal section of the thoracoabdominal aorta showing multiple mycotic aneurysms. Aneurysm in the distal aortic arch causing obstruction of the left subclavian artery is appreciated. Right, Three-dimensional reconstruction of postoperative images showing good collateralization of the mesenteric arteries and the left renal arteries.

\section{DISCUSSION}

At Boston City Hospital, over a 50-year period, 22,792 necropsies were performed, 338 aortic aneurysms were identified, and only 1 was tubercular in origin. ${ }^{1}$ Choudhary and colleagues, ${ }^{2}$ in their review of 88 patients with tuberculous aneurysm, showed that the abdominal aorta is most commonly involved and 1 patient had thoracoabdominal aorta involvement. In 4 patients, the aneurysms were multiple. Mycotic tuberculous aneurysm of thoracoabdominal aorta extending from the aortic arch with multiple

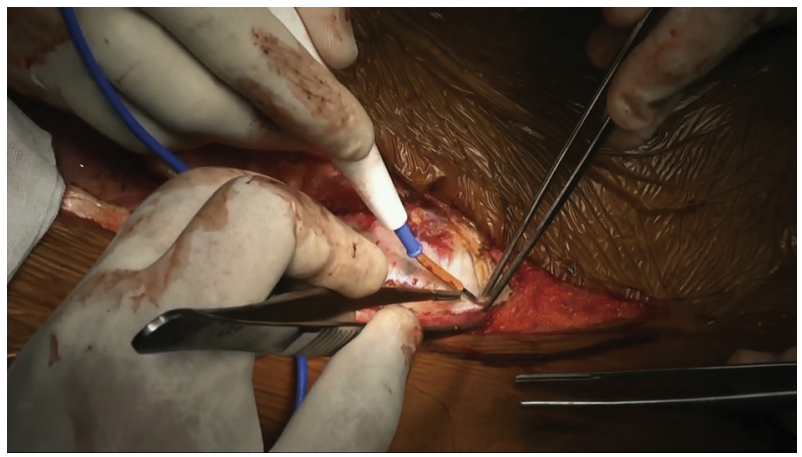

VIDEO 1. Surgical procedure for multiple tuberculous mycotic aneurysms. outpouching is rare, and to the best of our knowledge this is the first case report discussing such involvement.

TB of larger arteries can present in various forms, including tubercular polyps, aneurysm formation, or a stenosing type of tubercular aortoarteritis. ${ }^{3,4}$ The aorta may be involved in the tubercular process either through hematogenous spread or by way of direct extension of the bacteria from adjacent organs. The mycobacterium may lodge in the atheromatous plaque through the bloodstream or invade through the vasa vasorum. Most commonly there is a direct extension from a contiguous tuberculous focus.

Mycotic tuberculous aneurysms need a multiple modality approach - surgery or endovascular replacement combined with medical treatment. Very few cases exist in the literature about the successful treatment of TB-related thoracoabdominal mycotic aneurysms. A few authors have reported use of endovascular grafts for treatment of tuberculous aneurysms, but this procedure needs long-term followup. ${ }^{5}$ The mainstay of antibiotic therapy is a 6- to 9-month regimen that includes isoniazid and rifampicin.

The optimal treatment of mycotic tuberculous aortic aneurysms remains complex. These aneurysms are rare, so it is unlikely that a single center will gain great experience in treating the condition; therefore, each patient should be 
treated on an individual basis. This case is being reported for its rare situation of multiple aneurysms involving the thoracoabdominal aorta due to mycobacterium and the successful treatment of the condition by open surgery. Based on our limited experience, we consider open graft replacement an appropriate treatment for TB-related thoracoabdominal aneurysm.

\section{References}

1. Parkhurst GF, Dekcer JP. Bacterial aortitis and mycotic aneurysm of the aorta; a report of twelve cases. Am J Pathol. 1955;31:821-35.

2. Choudhary SK, Bhan A, Talwar S, Goyal M, Sharma S, Venugopal P. Tubercular pseudoaneurysms of the aorta. Ann Thorac Surg. 2001;72:1239-44.

3. Haythorn SR. Tuberculosis of the large arteries. JAMA. 1913;60:1413-6.

4. Gajraj A, Victor S. Tuberculous aorta arteritis. Clin Radiol. 1981;32:461-6.

5. Han DK, Chung C, Walkup MH, Faries PL, Marin ML, Ellozy SH. Endovascular stent-graft repair of a tuberculous mycotic aortic aneurysm. Ann Vasc Surg. 2011; 25:699.e13-6.

\title{
EDITORIAL COMMENTARY
}

\section{Tuberculous aneurysm of the aorta: Rare but treatable}

\author{
Nicholas T. Kouchoukos, MD
}

\footnotetext{
From the Division of Cardiovascular and Thoracic Surgery, Missouri Baptist Medical Center, BJC HealthCare, St Louis, Mo.

Disclosures: Author has nothing to disclose with regard to commercial support.

Received for publication June 21, 2016; accepted for publication June 22, 2016; available ahead of print July 20, 2016.

Address for Reprints: Nicholas T. Kouchoukos, MD, Cardiac, Thoracic, and Vascular Surgery Inc, 3009 N Ballas Rd, Suite 360C, St Louis, MO 63131 (E-mail: ntkouch@aol.com).

J Thorac Cardiovasc Surg 2016;152:e98-9

$0022-5223 / \$ 36.00$

Copyright $₫ 2016$ by The American Association for Thoracic Surgery

http://dx.doi.org/10.1016/j.jtcvs.2016.06.045
}

In this issue of the Journal, Velayudhan and colleagues ${ }^{1}$ report on the surgical treatment of a relatively rare but important cause of aortic aneurysm, tuberculosis. ${ }^{1}$ Treatment of this condition is of particular importance in countries such as India, the source of this report, where tuberculosis remains a major health problem. Velayudhan and colleagues ${ }^{1}$ successfully replaced the distal arch and the entire descending thoracic and abdominal aorta of an 18-year-old male patient with multiple presumed pseudoaneurysms as well as occlusion of the left subclavian, right renal, and inferior mesenteric arteries. The procedure was carried out under total hypothermic cardiopulmonary bypass with a short interval of circulatory arrest. The ostial stenosis of the left renal artery was corrected with an interposition polyester graft, and several pairs of lower intercostal arteries were implanted into the aortic graft. The heart was protected with a cold cardioplegic solution after clamping of the ascending aorta. As a minor technical point, at my institution we prefer hypothermic ventricular fibrillation with left-heart venting for myocardial protection during these procedures, which avoids the need for clamping of the ascending aorta and provides adequate protection. ${ }^{2}$

Up until 1999, only 88 cases of tuberculous aneurysms of the aorta had been reported in the English language

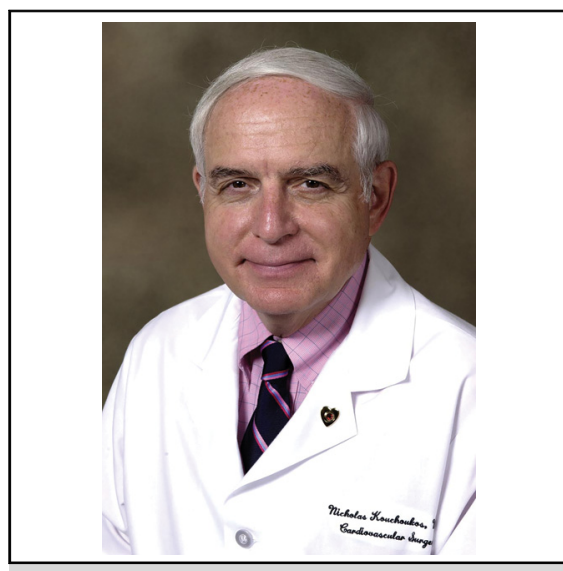

Nicholas T. Kouchoukos, MD

\section{Central Message}

Tuberculous aneurysm of the aorta can be successfully treated with open or endovascular repair and long-term drug therapy.

See Article page e95. literature. ${ }^{3}$ Most of these lesions are pseudoaneurysms, and they most commonly develop by invasion of the aortic wall from contiguous foci of tubercular tissue (lymph nodes, paravertebral abscesses) or by the hematogenous route. Successful treatment has involved graft replacement of the involved aortic segments combined with long-term multimodal drug therapy. More recently, tuberculous aneurysms confined to the descending thoracic and infrarenal abdominal aorta have been 